\title{
Pink Patches With a Hyperpigmented Rim
}

Ramiz N. Hamid, MD, MPH; Ahmad I. Aleisa, MD; Dirk M. Elston, MD

\section{Eligible for 1 MOC SA Credit From the ABD}

This Photo Challenge in our print edition is eligible for 1 self-assessment credit for Maintenance of Certification from the American Board of Dermatology (ABD). After completing this activity, diplomates can visit the ABD website (http://www.abderm.org) to self-report the credits under the activity title "Cutis Photo Challenge." You may report the credit after each activity is completed or after accumulating multiple credits.

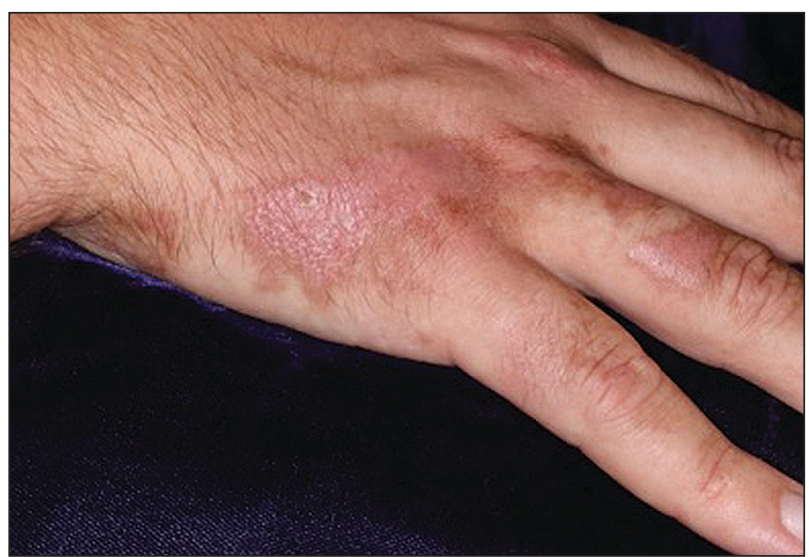

A 25-year-old man presented with a rash on the right hand, chest, abdomen, right thigh, and ankles of 2 weeks' duration. He reported that the eruption began with bullous lesions following a boat trip. The bullae ruptured over the next several days, and the lesions evolved to the current appearance. Although the patient had experienced pain at the site of active blisters, he denied any current pain, itching, or bleeding from the lesions. No other medical comorbidities were present.

\section{WHAT'S YOUR DIAGNOSIS?}

a. allergic contact dermatitis

b. bullous fixed drug eruption

c. bullous lupus erythematosus

d. phytophotodermatitis

e. porphyria cutanea tarda

Dr. Hamid is from the Department of Dermatology, Wake Forest School of Medicine, Winston-Salem, North Carolina. Drs. Aleisa and Elston are from the Department of Dermatology and Dermatologic Surgery, Medical University of South Carolina, Charleston.

The authors report no conflict of interest.

Correspondence: Ramiz N. Hamid, MD, MPH, Department of Dermatology, Wake Forest School of Medicine, 4618 Country Club Rd,

Winston-Salem, NC 27104 (rhamid@wakehealth.edu).

doi:10.12788/cutis.0163 


\section{THE DIAGNOSIS: Phytophotodermatitis}

$\Lambda$ more detailed patient history revealed that there was beer with limes on the boat, but the partygoers neglected to bring a knife. The patient volunteered to tear the limes apart with his bare hands. Because he was clad only in swim trunks, lime juice splattered over various regions of his body.

Phytophotodermatitis is a phototoxic blistering rash that follows topical exposure to plant-derived furocoumarins and sunlight (Figure). Furocoumarins are photosensitizing substances produced by certain plants, possibly as a defense mechanism against predators. ${ }^{1}$ They cause a nonimmunologic phototoxic reaction when deposited on the skin and exposed to UVA radiation. Exposure to limes is the most common precipitant of phytophotodermatitis, but other potential culprits include lemons, grapefruit, figs, carrots, parsnips, celery, and dill. ${ }^{2}$

Lesions associated with phytophotodermatitis classically present as painful erythematous patches and bullae in regions of furocoumarin exposure. Affected areas are well demarcated and irregularly shaped and heal with a characteristic hyperpigmented rim. They often have a downward streak pattern from the dripping juice. ${ }^{3}$ If the furocoumarins are transferred by touch, lesions can appear in the shape of handprints, which may raise alarms for physical abuse in children. ${ }^{4}$

Photochemical reactions caused by activated furocoumarins cross-link nuclear DNA and damage cell membranes. These changes lead to cellular death resulting in edema and destruction of the epidermis. Other effects include an increase in keratin and thickening of the stratum corneum. The hyperpigmentation is a result of increased concentration of melanosomes and stimulation of melanocytes by activated furocoumarins. ${ }^{5}$

Management of phytophotodermatitis depends on the severity of skin injury. Mild cases may not require any treatment, whereas the most severe ones require admission to a burn unit for wound care. Anti-inflammatory medications are the mainstay of therapy. Our patient was prescribed desonide cream $0.05 \%$ for application to the affected areas. Sunscreen should be applied to prevent worsening of hyperpigmentation, which may take months to years to fade naturally. If hyperpigmentation is cosmetically troubling to the patient, bleaching agents such as hydroquinone and retinoids or Nd:YAG laser can be used to accelerate the resolution of pigment. ${ }^{5}$

Phototoxicity differs from less common photoallergic reactions caused by preformed antibodies or a delayed cellmediated response to a trigger. The classic presentation of photoallergy is apruritic, inflammatory, bullous eruption in a sensitized individual. ${ }^{6}$ Allergic contact dermatitis more commonly is associated with pruritus than pain, and it presents as a papulovesicular eruption that evolves into

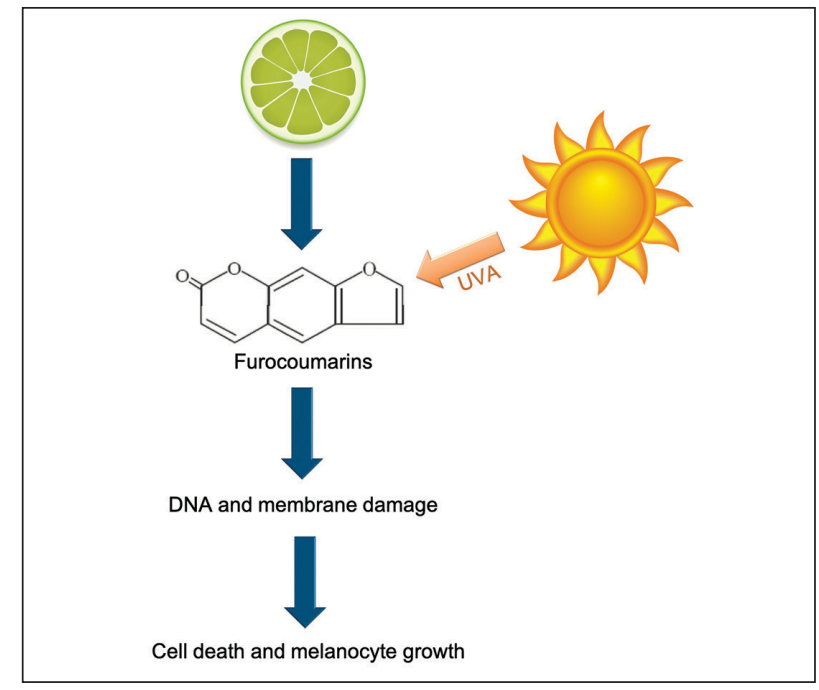

UVA radiation activates furocoumarins, creating an inflammatory response that results in death of skin cells and hyperpigmentation.

lichenified plaques. ${ }^{7}$ Porphyria cutanea tarda would likely be accompanied by other cutaneous features such as hypertrichosis and sclerodermoid plaques with dystrophic calcification, in addition to wine-colored urine-containing porphyrins. ${ }^{8}$ Bullous fixed drug eruptions develop within 48 hours of exposure to a causative agent. The patient typically would experience pruritus and burning at the site of clearly demarcated erythematous lesions that healed with hyperpigmentation. ${ }^{9}$ Lesions of bullous lupus erythematosus may appear in areas without sun exposure, and they would be more likely to leave behind hypopigmentation rather than hyperpigmentation. ${ }^{10}$

\section{REFERENCES}

1. Pathak MA. Phytophotodermatitis. Clin Dermatol. 1986;4:102-121.

2. Egan CL, Sterling G. Phytophotodermatitis: a visit to Margaritaville. Cutis. 1993;51:41-42.

3. Hankinson A, Lloyd B, Alweis R. Lime-induced phytophotodermatitis [published online ahead of print September 29, 2014]. J Community Hosp Intern Med Perspect. doi:10.3402/jchimp.v4.25090

4. Fitzpatrick JK, Kohlwes J. Lime-induced phytophotodermatitis. J Gen Intern Med. 2018;33:975.

5. Weber IC, Davis CP, Greeson DM. Phytophotodermatitis: the other "lime" disease. J Emerg Med. 1999;17:235-237.

6. Monteiro AF, Rato M, Martins C. Drug-induced photosensitivity: photoallergic and phototoxic reactions. Clin Dermatol. 2016;34:571-581.

7. Tan CH, Rasool S, Johnston GA. Contact dermatitis: allergic and irritant. Clin Dermatol. 2014;32:116-124.

8. Dawe R. An overview of the cutaneous porphyrias. F1000Res. 2017;6:1906.

9. Bandino JP, Wohltmann WE, Bray DW, et al. Naproxen-induced generalized bullous fixed drug eruption. Dermatol Online J. 2009;15:4.

10. Contestable JJ, Edhegard KD, Meyerle JH. Bullous systemic lupus erythematosus: a review and update to diagnosis and treatment. Am J Clin Dermatol. 2014;15:517-524. 